\title{
EVALUATION OF BATTERY AND BATTERY CHARGER SHORT-CIRCUIT CURRENT CONTRIBUTIONS TO A FAULT ON THE DC DISTRIBUTION SYSTEM AT A NUCLEAR POWER PLANT
}

\section{TASK 1 REPORT: LITERATURE REVIEW}

\section{March 2015}

Prepared by

Brookhaven National Laboratory

Nuclear Sciences and Technology Department

Upton, New York 11973

BNL Project Manager - Bill Gunther

Prepared for

U.S. Nuclear Regulatory Commission

Project HQ-60-14-D-0023

NRC Project Manager - Liliana Ramadan 
BNL Technical Report

BNL-107800-2015-IR

This report was prepared as an account of work sponsored by an agency of the United States Government. Neither the United States Government nor any agency thereof, nor any of their employees, nor any of their contractors, subcontractors, or their employees, makes any warranty, express or implied, or assumes any legal liability or responsibility for the accuracy, completeness, or any third party's use or the results of such use of any information, apparatus, product, or process disclosed, or represents that its use would not infringe privately owned rights. Reference herein to any specific commercial product, process, or service by trade name, trademark, manufacturer, or otherwise, does not necessarily constitute or imply its endorsement, recommendation, or favoring by the United States Government or any agency thereof or its contractors or subcontractors. The views and opinions of authors expressed herein do not necessarily state or reflect those of the United States Government or any agency thereof. 


\section{EXECUTIVE SUMMARY}

Inherent in designing and maintaining short-circuit protection in a DC distribution system protection is knowing what the contributions are from the station battery and battery charger(s), the major sources of direct current to a fault on the DC distribution system. There is an extensive amount of literature dealing with this subject in the form of industry guidance or standards, journal articles, and test reports. The purpose of this BNL technical report is to review these sources and summarize the information that is relevant to better understanding the expected contributions from batteries and battery chargers in response to a fault on a DC distribution system at a nuclear power plant.

The review of the literature revealed several interesting factors associated with this general subject including:

1. Industry guidance and standards (summarized in Table 1) differ somewhat with regard to the magnitude of the short-circuit currents to be expected from a vented lead acid battery and the combined effect from the battery charger and battery when they are connected in parallel (the typical configuration for a nuclear power plant). Some publications indicate that a conservative rule of thumb approach is sufficient while others recommend more precise calculations that take into account DC distribution system resistance and inductance.

2. These same industry standards are based on a limited amount of testing and other empirical data. IEEE 141-1993 states that "Simplified procedures for the calculation of DC short-circuit currents are not well established." Since many of the DC distribution systems in the current commercial nuclear reactor fleet were designed before 1993, there may not have been a uniform approach taken to calculating the expected contributions from battery chargers and batteries when designing the short-circuit protection schemes for the DC distribution system.

3. Journal articles written on the subject over the past twenty years provide similar methods to calculate short-circuit current contributions and provide approaches on how best to configure protection in a DC distribution system. The overall goal cited is to isolate the fault as close to the occurrence as possible in order to minimize the impact on other equipment and facility operations. Software has been developed to assist with these calculations where the complexity of the DC distribution system warrants it.

4. The articles that describe testing that has been performed on vented lead acid cells and a battery charger show that the general rules of thumb for calculating short-circuit currents yield values that are higher than the actual fault current that will be realized. While the higher fault current values determined by using the rules of thumb may be considered to be "conservative", they may have shortcomings when considering the overall system response to a fault condition. For example, a few articles discuss the potential for a cable fire if the protection settings are based on overly conservative (too high) settings that would increase the fault interruption time. 
5. The rate of rise of the fault current (time constant in milliseconds) is dependent on the DC distribution circuit characteristics. According to the technical papers reviewed, knowledge of this time constant (which is a function of the circuit inductance) is important when selecting the settings of the protective devices.

6. Plants that have increased the capacity of their battery strings in order to accommodate the additional loads that have been added to the DC distribution system over the life of the plant may also need to upgrade their protective devices to ensure that their interruption ratings are satisfactory for the larger battery fault current that will be produced.

This report summarizes the information about the short-circuit currents associated with vented lead-acid batteries and battery chargers and categorizes the sources of this information. No testing data were found where a short circuit was applied to a battery and a battery charger in combination. The phase 3 work planned will therefore offer new information that should be useful to the NRC and the nuclear industry in general. 


\section{TABLE OF CONTENTS}

EXECUTIVE SUMMARY iii

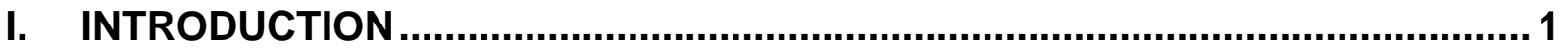

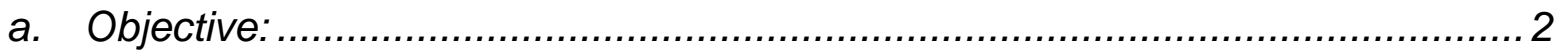

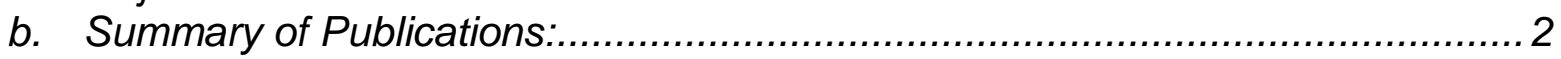

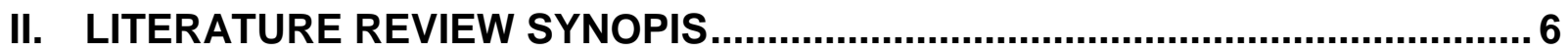

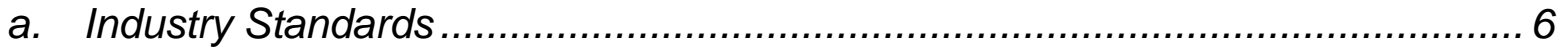

b. Journal Articles and Conference Proceedings - (Testing Related) .................. 17

c. Journal Articles and Conference Proceedings - (Non-Testing Related) .......... 20

d. Vendor Publications and Communications................................................... 28

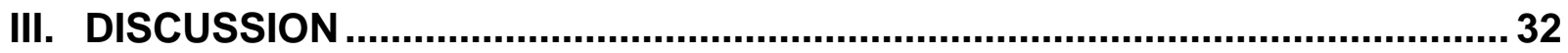

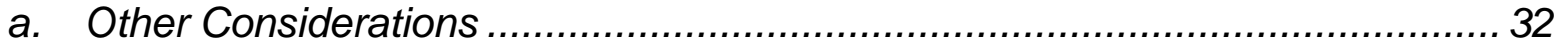

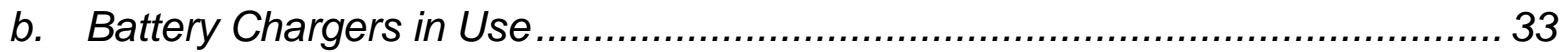

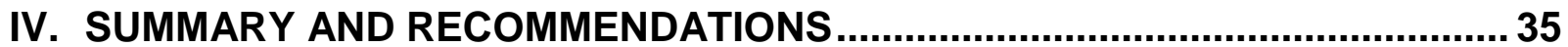




\section{LIST OF FIGURES}

Page

Figure1: $\quad$ Sample dc one-line diagram from IEEE 399-1997 ........................... 8

Figure 2: Excerpt from IEEE Standard 946-2004 ….................................... 13

Figure 3: Example DC System for a Fault Study (EPRI TR-100248)................... 23

Figure 4: Sample Battery Vendor Short-Circuit Data ........................................ 29

Figure 5: Early Battery Response to a Short Circuit ...................................... 30 


\section{LIST OF TABLES}

Page

Table 2: Summary of Industry Standards Information Related to DC System Faults ........................................................................ 16

Table 2: $\quad$ 300A SCR-Type Battery Charger Short-circuit Contributions:

Summary of Testing Results

Table 3: $\quad$ Short-Circuit Test Results of an AT\&T Battery (Excerpted from paper) ............................................................ 19

Table 4: Battery Charger Types Used in Nuclear Power Plants (1994 Source) . 33

Table 5: $\quad$ Class IE Battery Chargers- EPIX Database (2014) .......................... 34 
BNL Technical Report

BNL-107800-2015-IR 


\section{INTRODUCTION}

On September 25, 2011 at the Palisades Nuclear Plant on the left train of DC power, both the battery charger and the battery tripped on overcurrent when a fault occurred on the downstream DC panel (Information Notice 2013-17). As a result of the event, a Special Inspection Team (SIT) was assembled. The complete details of this event are provided in the SIT Report (ADAMS Accession No. ML113330802). Page 47 of the SIT report, the following is states:

According to Ametek, the manufacturer of the battery charger, the current-limiting feature of the battery chargers were not immediate (38 millisecond time delay) and were not designed to protect against large, instantaneous DC faults. Because the fault current was very high, the battery charger tripped before the current limiter was able to respond and compensate. This phenomenon was also discussed in IEEE-946-2004, "IEEE Recommended Practice for the Design of DC Auxiliary Power Systems for Generating Station.

IEEE Standard 946-2004 Subclause 7.9.2 states: "When the battery charger is connected in parallel with the battery, the battery capacitance will prevent the battery charger contribution from rising instantaneously. Therefore the maximum current that a charger will deliver on short circuit will not typically exceed $150 \%$ of the charger full load ampere rating. Instantaneous battery charger current rise should only become a concern during periods when the battery is disconnected." The statements in IEEE 9462004 related to the nature of these contributions may be contrary to what actually transpired at the Palisades Plant in September 2011, although there remains some uncertainty about exactly what transpired during that event. Nevertheless, there is a need to determine whether the individual short-circuit current contributions of a battery and a battery charger are independent of each other in a typical nuclear power plant DC distribution system configuration. This is necessary so that engineering measures such as protective device coordination can limit the impacts of such an event. The NRC staff currently considers that the statement in IEEE Std. 946-2004, Subclause 7.9.2, "Instantaneous battery charger current rise should only become a concern during periods when the battery is disconnected," is incorrect and is being applied erroneously. The staff believes that instantaneous battery charger current rise should be dependent only on the battery charger design and not whether the battery is connected or disconnected. Therefore, the battery charger short-circuit protection should take into consideration the initial short-circuit current rise during the first approximately 100 milliseconds of the fault occurrence.

The NRC issued Information Notice (IN) 2013-17 on September 6, 2013. This IN described the event that occurred at the Palisades Plant in September 2011 and encouraged licensees and applicants to review their design to insure that a fault similar to that which occurred at Palisades would not degrade the performance of their DC electrical distribution system. 


\section{a. Objective}

The overall objective of this task is to conduct an extensive literature search that includes technical papers, reports of previous testing, and detailed information about dc power distribution short-circuit protection, focusing on the contributions to a fault from battery chargers and batteries. This BNL technical report documents the review and analysis of these documents and provides recommendations for incorporating this information into the short-circuit testing that will be conducted.

\section{b. Summary of Publications}

The following publications (including email and correspondence) were reviewed and are described in this report.

\section{Industry Standards:}

1. IEEE Standard 141-1993; IEEE Recommended Practice for Electric Power Distribution for Industrial Plants; describes the importance of knowing the magnitude of available DC short-circuit current in the design and application of protective devices.

2. IEEE Standard 242-2001; IEEE Recommended Practice for Protection and Coordination of Industrial and Commercial Power Systems; provides basics on the nature of short-circuit currents and the process for establishing protection coordination.

3. IEEE Standard 399-1997; IEEE Recommended Practice for Industrial and Commercial Power Systems Analysis; this recommended practice commonly known as the "Brown Book" is a general treatise on power systems analysis theory. The 1997 version of this Standard includes a new chapter entitled "DC auxiliary power systems analysis".

4. IEEE Standard 666-1991; IEEE Design Guide for Electric Power Service Systems for Generating Stations; Provides info a fault contributions from batteries and battery chargers. Includes annexes with calculating short-circuit currents in a DC system.

5. IEEE Standard 946-2004; IEEE Recommended Practice for the Design of DC Auxiliary Power Systems for Generating Stations; discusses the available shortcircuit current from batteries and battery chargers and contains several annexes on how to calculate the magnitude of these currents.

6. IEEE Standard 1375-1998; IEEE Guide for the Protection of Stationary Battery Systems; this guide discusses the short-circuit characteristics of batteries and battery chargers and provides guidance for the protection of battery systems.

7. IEC Standard 61660; Short-circuit currents in dc auxiliary installations in power plants and substations; Two volumes- volume 1: Calculation of short-circuit currents. Volume 2: Calculation of effects such as electromagnetic forces, stresses on supports, and thermal effects on conductors and electrical equipment. 
8. NEMA PE 5-2003; Utility Type Battery Chargers; This standard covers the design attributes for battery chargers used to supply DC power from an AC source to charge a float-type battery and simultaneously power the connected utility system load.

\section{Testing-Related Documents:}

1. Short-Circuit Test Results of Current Limiting SCR Type Battery Charger, Kurt Uhlir, 1994 American Power Conference, Chicago, IL April 27, 1994.

2. Short-Circuit Characteristics of Large Lead Acid Storage Batteries, Kurt Uhlir and Mark Bowman, 1991 Northeast Electric Utility Battery Conference, Albany, NY, September 25, 1991.

3. Short-Circuit Current Test Results on AT\&T Round Cells at Different Temperatures by K. A. Murugesamoorthi, R. Landwehrle, and M. Migliaro; Telecommunications Energy Conference, INTELEC '93. 15th International (Volume: 2).

4. Correspondence from C. Seyer of Power Conversion Products dated 10/4/91; Short-circuit current from a 130V/300A Class IE SCR-type charger.

\section{Journal Articles and Conference Papers (Non-Testing):}

1. Analysis of Battery Cable Faults using a Dynamic Battery Model; N. Medora and A. Kusko, Battcon 2007. Expresses view that if the protection settings are too conservative, the short-circuit current may not actuate the protective device in a short enough time to prevent damage or even a fire.

2. Stationary Battery and DC Power System Electrical Protection Design Considerations, Kurt Uhlir, BATTCON 2003, National Battery Conference, Marco Island, Florida, April 28, 2003

3. EPRI Stationary Battery Guide, Rev. 2 of TR-100248, W. E. Johnson, August 2002; Chapter 7 is entitled "DC Power Protection".

4. Understanding Short-Circuit Currents in DC Power Systems When Used in Conjunction with Standby Batteries, Ron Mollet et al, Telecommunications Energy Conference, 2002. INTELEC. 24th Annual International, 2002. This paper describes the need to understand the magnitude of possible short circuits in a dc system and states that little data had been published by battery manufacturers on the potential short-circuit current capabilities of their products.

5. Short-Circuit Current Calculations for DC Systems by A. Berizzi et al; IEEE Transactions on Industry Applications, 1996. This paper describes the method used to calculate short-circuit currents provided by the IEC standard 60061-1.

6. Transient Analysis of Auxiliary DC Installations in Power Plants and Substations, Srdjan Skok et al; 2004 IEEE/PES Transmission and Distribution Conference and Exposition. This paper deals with the risk of power system blackout caused by auxiliary DC installation failure. 
7. Stationary Battery Charger Specification Demystified, William Bennett, Battcon 2003. States that an active current limit circuit is a capable defense to protect the charger from a fault on the dc bus. Also states that the charger output filter capacitor can clear dc fuses in the output circuit when it discharges into a dc bus fault.

8. Battery Protection Methods - Important Variables to Consider, R. Setchell et al, Battcon 2001. This paper presents recommended battery protection practices to accurately protect the battery an associated DC plant, operations, and personnel.

9. Overcurrent Protection of DC Power Plant Equipment Using Modern High Performance Current Limiting Fuses, Ron Mollet, Intelec 1995. Describes the use of current limiting fuses for better fault isolation and equipment protection.

10. DC Overcurrent Protection-Where We Stand, James Brozek, IEEE Transactions on Industry Applications, Volume 29, Issue 5, 1993. States that the task of selecting short-circuit for DC systems is not straightforward because manufacturer's published data is usually based on AC ratings that require the user to determine the DC applicability.

11. Battery Protection-Where do we Stand?; Richard Nailen, IEEE Transactions on Industry Applications, Vol. 27, No. 4, 1991. This very descriptive paper is frequently referenced by others. It discusses the consequences of battery failures and identifies a weakness in the IEEE standards concerning battery protection.

12. DC Control Battery System Protection and Coordination, Robert Smith; Industrial and Commercial Power Systems Technical Conference, 1993. The author states that battery system failure jeopardizes a power system by eliminating the DC control power source for AC system circuit breakers and protective devices. He reviews the protection of control battery system components including the battery, battery charger and individual circuits and discusses battery system protective device coordination.

13. The Effectiveness of Using IEC61660 for Characterizing Short-Circuit Currents of Future Low Voltage DC Distribution Networks, A. Emhemed and G. Burt; $22^{\text {nd }}$ International Conference on Electricity Distribution. June 2013. This paper presents the challenges of understanding fault behavior and effective protection systems and using IEC61660 for characterizing low voltage DC networks.

14. Battery and DC Backup System Protection Coordination by Haissam Nasrat; 2011 InfoBATT conference presentation. This presentation focuses on the need for and approaches to ensure proper protection coordination in a DC distribution system.

15. Handbook of Electrical Calculations, $3^{\text {rd }}$ Edition; Section 18, Stationary Batteries, M. Migliaro. This reference contains basic information about battery sizing, operation, and construction. It contains a section on calculating battery shortcircuit current that is described in this report. 


\section{Vendor Information:}

1. "Battery Short-Circuit Current," RS 1468, C\&D Charter Power Systems Inc., March 1996. This publication from C\&D describes the short-circuit characteristics of lead acid batteries and provides examples for calculating the available short-circuit current from a battery.

2. Enersys correspondence and publication of short-circuit values; specification sheet from a battery vendor showing the internal resistance of the cell and the ideal (conservative) short-circuit current.

3. Correspondence from C\&D to FP\&L dated 7/30/91 stating that the current limit "should hold" if a short circuit is applied to the charger while it is operating. 


\section{LITERATURE REVIEW SYNOPIS}

\section{a. Industry Standards}

This section examines the relevant industry consensus documents that provide guidance and recommendations related to battery or battery charger fault contributions and the use protective devices and coordination in dc distribution circuits. IEEE is the source of most of these documents, but one international standard (IEC 61660) and one manufacturer's standard (NEMA PE-5) are also included.

1. IEEE Standard 141-1993; IEEE Recommended Practice for Electric Power Distribution for Industrial Plants; Sponsored by the Power Systems Engineering Committee of the Industrial and Commercial Power Systems Department of the IEEE Industry Applications Society

In Section 4.8, entitled "Calculation of short-circuit currents for DC systems," IEEE Std 141-1993 states that the calculation of DC short-circuit currents is essential in the design and application of distribution and protective apparatus used in DC systems. Knowledge of mechanical stresses imposed by these fault currents is also important in the installation of cables, buses, and their supports. This latter item is outside the scope of the fault current testing project but brings to the forefront the significant amount of energy that is produced in a fault situation that can be manifested in quantities of heat enough to initiate a fire and movement enough to break bus or cable connections.

As in the application of AC protective devices, the magnitude of the available DC shortcircuit current is the prime consideration. Since high-speed DC protective devices can interrupt the flow of fault current before the maximum value is reached, it is necessary to consider the rate of rise of the fault current, along with the interruption time, in order to determine the maximum current that will actually be obtained. This is another variable that DC distribution designers need to consider in nuclear power plant systems. Lower speed protective devices will generally permit the maximum value to be reached before interruption.

The sources of DC short-circuit currents identified by the Standard are the following:
a. Generators
b. Synchronous converters
c. Motors
d. Battery Chargers
e. Batteries

IEEE Std 141-1993 states that "Simplified procedures for the calculation of DC shortcircuit currents are not well established"; it only provides reference to other publications containing helpful information such as ANSI C97.1-1972, IEEE Std C37.5-1979, IEEE Std C37.41-1988, NEMA AB 1-1975, and NEMA SG 3-1981. Most of these have been superseded by other documents. 
2. IEEE Standard 242-2001; IEEE Recommended Practice for Protection and Coordination of Industrial and Commercial Power Systems. (Also known as the "Buff Book"); Sponsored by the Industrial and Commercial Power Systems Department of the IEEE Industry Applications Society

Section 2.2 of the Standard discusses how the designer may have several objectives in mind when calculating a short-circuit current. While "the worst case" current is the goal, the set of assumptions that leads to a worst case calculation for one purpose may not yield worst-case results for another purpose. While most of the discussion in this Standard is related to AC circuits, the guidance for performing a coordination study would apply to DC distribution systems as well since the goal in both is to isolate the fault as close to its location as possible and thereby minimize the impact on the rest of the system.

This Standard describes in great detail the operation of protective relays, breakers and fuses. For most battery protection applications, it states that fuse operation is straightforward and reliable because batteries contain little inductance and a shorted battery is similar to a fault through a resistor. It notes in Section 5.8.7.7 that "A shorted battery drains rapidly and gives rise to high di/dt."

Design features common to both $\mathrm{AC}$ and $\mathrm{DC}$ distribution circuits that are explained in the Standard are:

- Quick isolation of the affected portion of the system while maintaining normal operation elsewhere,

- Reduction of the short-circuit current to minimize damage to the system, its components, and the utilization equipment it supplies, and

- Use of alternate circuits, automatic throwovers, and automatic reclosing devices to improve overall system reliability.

3. IEEE Standard 399-1997; IEEE Recommended Practice for Industrial and Commercial Power Systems Analysis; Sponsored by the Power Systems Engineering Committee of the IEEE Industry Applications Society

This recommended practice is a reference source for engineers involved in industrial and commercial power systems analysis who need to perform power system studies of short-circuits, load flows, and protective coordination among others. This Standard is known as the "Brown Book" and was modified in 1997 to add Chapter 16, "DC auxiliary power system analysis."

In Chapter 16, information relevant to battery and battery charger load flow and shortcircuit response are presented referencing a typical DC distribution system that is replicated here as Figure 1. The authors note that it is the intent of the chapter to consolidate information from other sources and provide guidance for performing DC power systems analysis. It puts forward the need to use software to address increasingly more complex DC systems. 


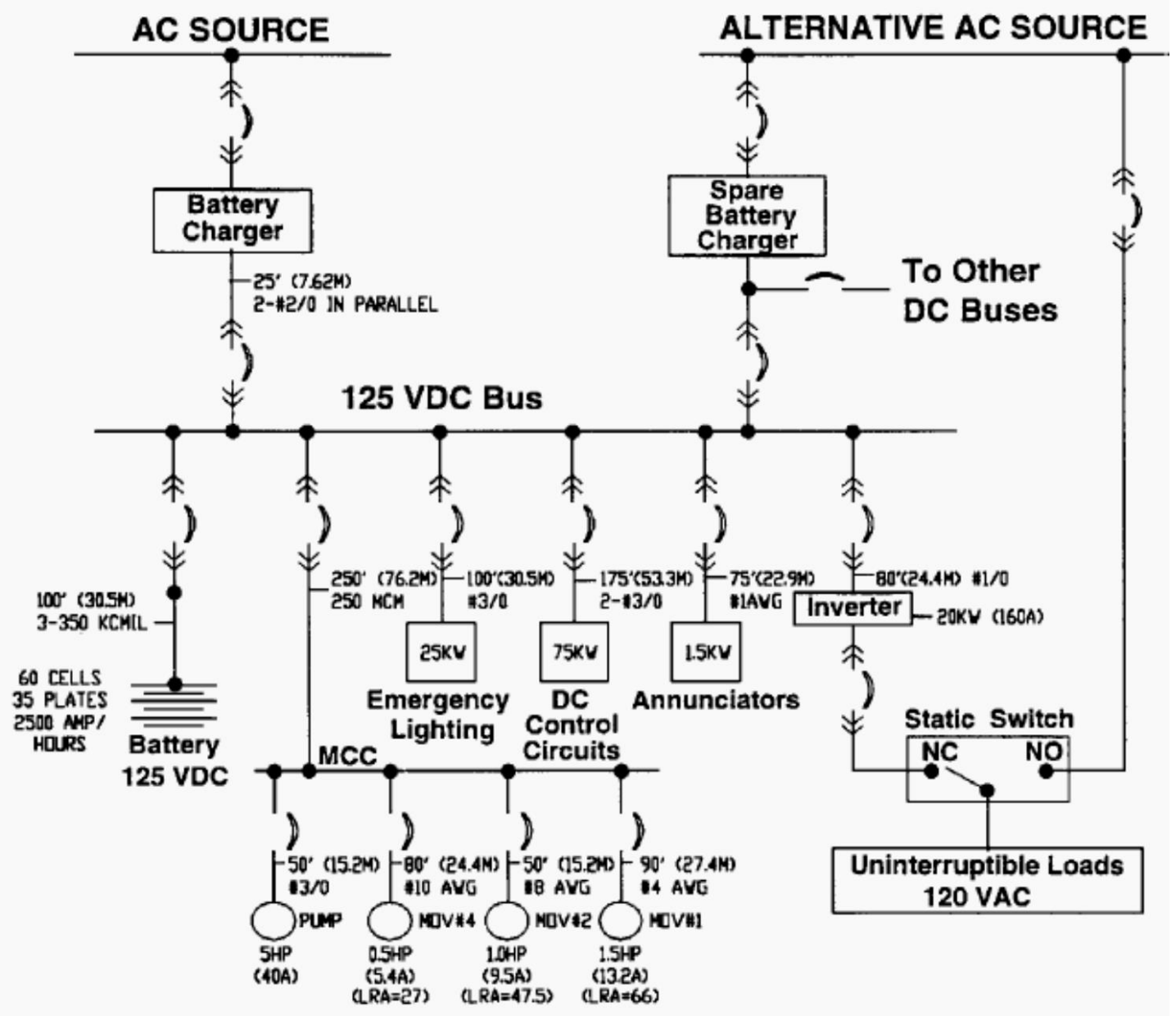

Figure 1: Sample dc one-line diagram from IEEE 399-1997

The document notes that load flow/voltage drop and short-circuit studies are "usually performed with different conductor temperatures assumed." Therefore, the resistance portions of the one-line diagrams for the various types of studies are typically not identical. It also notes that short-circuit calculations require inductance values for all elements if the short-circuit time constant and rate of rise are to be calculated.

IEEE Std. 399-1997 states that the peak short-circuit current that a battery can deliver is limited by its internal resistance, including the intercell connectors. The greater the battery's resistance, the lower the peak short-circuit value. The rise time is dependent on the ratio of the battery's inductance to its reactance. It goes on to say that battery cell inductance values have been obtained from testing on lead acid cells ranging from 10-1600 Ah. For cells greater than $1300 \mathrm{Ah}$, an inductance of $0.145 \mu \mathrm{H} / \mathrm{cell}$ can be used.

The Standard goes on to describe the battery chargers contribution to DC system shortcircuits. It refers to IEEE Std. 946-1992 in stating that for a typical DC system, the short-circuit current from a battery charger will peak and decay before the short-circuit current from the battery reaches its peak. It goes on to discuss the impact of the charger 
design on the short-circuit contribution; namely, that in some charger designs the transient can be as short as $8 \mathrm{~ms}$, and in others it has been shown to last as long as $100 \mathrm{~ms}$. (No test reference cited for this statement). Steady state short-circuit current is conservatively calculated as the sum of the peak short-circuit current from the battery and the current limit value from the charger.

4. IEEE Standard 666-1991; IEEE Design Guide for Electric Power Service Systems for Generating Stations; Sponsored by the Energy Development and Power Generation Committee of the IEEE Power Engineering Society

This guide explains what good design practices are for the many different types of electric power service systems installed in power generating stations. The authors anticipated that this guide will assist those who must establish the criteria for the design of generating station auxiliaries and their electric power service.

This Standard states that in order to control damage and minimize shutdown time, the available fault current must not exceed the ratings of the auxiliary power system equipment, and the fault should be quickly isolated from the auxiliary system. The magnitude of the fault current to be allowed on the system must be established and accommodated in the design during the conceptual design stage. The circuit switching devices must be able to handle the interruption of fault currents and isolate the fault from the "unfaulted" portions of the system.

Section 6.10 of the Standard discusses DC fault currents. It states that the sources of fault current, the fault current waveforms, and the equipment used to interrupt and isolate faults are inherently different from the treatment of faults on an AC system. Section 6.10.4 presents a procedure for calculating the expected magnitude of a DC fault. For battery chargers, it simply says that the maximum fault current should be obtained from the vendor. If that is not available, then the current limit value should be used.

For batteries, the Standard describes the equivalent circuit of the battery as represented by the series combination of the internal resistance $\left(R_{A}\right)$ of the battery, the resistance $\left(R_{C}\right)$ of the conductor that connects the cells together, the inductance $\left(L_{C}\right)$ of the conductors, and the battery internal voltage $\left(E_{B}\right)$. The cell internal resistance should be obtained from the manufacturer. $R_{C}$ and $L_{C}$ depend on the conductor size, length, and composition. The battery internal voltage used should be obtained from the manufacturer and should be the lowest value to which the voltage will drop when the cell is suddenly placed under a heavy load. It assumes that the charger will go into current limit and will not be able to hold cell voltage at its normal service value.

This Standard also states that when multiple sources are connected to a bus with negligible resistance, and a fault occurs on the bus, it is assumed that one source has no effect on the other source, and the total short-circuit current can be determined by constructing a current time curve for each source and adding the curves graphically. In most practical cases, a short circuit will result in the current from all of the sources flowing together through some of the same system elements. Since the currents share a common path, the calculation of the currents should take the entire system into account at all times. 
5. IEEE Standard 946 - 2004; IEEE Recommended Practice for the Design of DC Auxiliary Systems for Generating Stations; Sponsored by the Energy Development and Power Generation Committee of the IEEE Power Engineering Society

This Standard contains the most extensive description of battery and battery charger short-circuits that we found. A Working Group has been established to review and revise this Standard and combine it with IEEE Std. 1375 which is described in the next section. Several excerpts are taken from the Standard that are directly associated with the short-circuit testing that will be performed by BNL for the NRC.

\section{Available Short-Circuit Current}

Section 7.9 of the Standard provides information for determining the maximum available short-circuit current. This calculation establishes the interrupting capacity for feeder breakers/fuses and the withstand capability of the distribution buses and disconnecting devices. The total short-circuit current is the sum of that delivered by the battery, battery charger, and motors (as applicable). When a more accurate value of maximum available short-circuit current is required, the Standard states that the analysis should account for interconnecting cable resistance.

\section{Batteries}

The Standard states that the current a battery will deliver on short circuit depends on the total resistance of the short-circuit path. A conservative approach in determining the short-circuit current that the battery will deliver at $25^{\circ} \mathrm{C}$ is to assume that the maximum available short-circuit current is 10 times the 1 minute ampere rating (to $1.75 \mathrm{~V}$ per cell at $25^{\circ} \mathrm{C}$ and specific gravity of 1.215 ) of the battery. When a more accurate value is required, the short-circuit current for the specific application should be calculated (provided in Annex C of the Standard) or actual test data should be obtained from the battery manufacturer. The batteries nominal voltage should be used when calculating the maximum short-circuit current. Tests have shown that an increase in electrolyte temperature (above $25^{\circ} \mathrm{C}$ ) or elevated battery terminal voltage (above nominal voltage) will have no appreciable effect on the magnitude of short-circuit current delivered by a battery (see Stationary Battery Short-Circuit Test Report [B22] and Stationary Battery Short-Circuit Test Report [B23]). (Note: these test reports that form the basis for this section of IEEE Std 946-2004 are discussed in Section B of this report along with other published testing results for batteries and battery chargers.)

\section{Battery Chargers}

The Standard states that the battery charger current-limit circuitry may require two AC cycles ( 32 milliseconds) to clamp. The maximum current that a charger will deliver into a short circuit after this period, coincident with the maximum battery short-circuit current, is determined by the charger current-limit circuit (as further described in Annex $E$ of the Standard). When the battery charger is connected in parallel with the battery, the battery capacitance will prevent the battery charger contribution from rising instantaneously. Therefore, according to this Standard, the maximum current that a charger will deliver on short circuit will not typically exceed $150 \%$ of the charger full load ampere rating. It also states that Instantaneous battery charger current rise should only 
become a concern during periods when the battery is disconnected. Confirming the interaction between the battery charger and the battery is one of the objectives of the testing program.

\section{Annex C: Batteries, Available Short-Circuit Current - Sample Calculations}

Annex $\mathrm{C}$ states that the current a battery will deliver on short circuit depends on the total resistance of the short-circuit path. It states that a conservative approach in determining the short-circuit current that the battery will deliver at $25^{\circ} \mathrm{C}$ is to assume that the maximum available short-circuit current is 10 times the 1 minute ampere rating (to $1.75 \mathrm{~V}$ per cell at $25^{\circ} \mathrm{C}$ and specific gravity of 1.215 ) of the battery. Note that the limited amount of testing (referenced in the Standard) found that the actual short-circuit current is less due to the battery and connector resistance. The Annex goes on to say that a more accurate value for the short-circuit current for the specific application may be calculated or actual test data may be obtained from the battery manufacturer. This is also stated in Section 7.9.1 of the Standard.

The total resistance is made up of two major parts as follows:

a. The "apparent" internal resistance of the battery

b. The external circuit resistance

The total internal resistance of the battery is equal to the sum of the internal resistance of the cells plus the resistances of the intercell connections. The value of internal cell resistance is a variable quantity that is significantly influenced by many factors; e.g., the temperature, the age, and the state of charge of the cell. The total external circuit resistance is the sum of the resistances of the various components; e.g., the connecting cables and the fault resistance.

\section{Annex E: Battery Charger, Short-Circuit Current Contribution}

This annex provides a rationale for determining the maximum value of the battery charger short-circuit current that will occur coincident with the maximum battery shortcircuit current. The reason for determining the maximum combined short-circuit current is to specify equipment with the correct interrupting rating that is suitable for the expected fault current. It is necessary to include the contributions from connected motors, battery chargers, and batteries when calculating the total short-circuit current for a fault in a DC system. An important point made in the Standard is that for a typical station battery and a current-limited charger, it can be shown that the peak short-circuit currents occur at different times so that the charger current-limited value added to the battery peak value provides a conservative total fault-current value. The fault current contribution from a typical battery charger is current-limited to a value not greater than $150 \%$ of the charger current rating. The timing of the fault contributions from the battery charger and the battery is another objective of the testing program.

The Annex states that tests on some current-limited SCR type battery chargers have shown that when the battery charger is isolated from a system, the initial short-circuit current can exceed the current-limited value. A large transient current spike may occur due to the stored energy in filter circuits (capacitors). This instantaneous peak short- 
circuit current may approach a value 200 times the charger rated current. However, the time duration of the initial transient current is short (in the order of $5 \mu \mathrm{s}$ ) and generally does not affect the ratings of equipment and protective devices. Unfortunately, the test data referred to is not cited in the references but may include the correspondence from Power Conversion Products described in Section II.B of this report.

Annex E of IEEE Standard 946-2004 goes on to say that in current-limited chargers, the current-limiting circuits will typically act to reduce the current after the first zero crossing (four-half cycles, $32 \mathrm{~ms}$, or less) if internal protective devices such as rectifier fuses have not already acted to clear the fault. It is, therefore, conservative to assume that the maximum sustained fault current after $32 \mathrm{~ms}$ is the current-limiting value, which is generally not greater than $150 \%$ of the charger current rating. The Annex does not indicate if this battery charger response is dependent on whether or not the battery is connected.

The fault current from a large lead storage battery resulting from a bolted short at the battery terminals will typically exhibit a rate-of-rise that delivers the peak current within 17 ms (see Stationary Battery Short-Circuit Test Report [B22] and Stationary Battery Short-Circuit Test Report [B23]). The fault current for a short at the DC distribution switchgear or panel board will peak later (typically within $34 \mathrm{~ms}$ to $50 \mathrm{~ms}$ ) due to the inductance of the DC system in series with the fault. The magnitude of the DC fault current for a short at the distribution bus will also be lower than the value at the battery due to the resistance of the cables between the battery terminals and the bus. The $N R C / B N L$ testing program will not be examining a fault at the distribution panel resulting in some uncertainty about the impact of the actual distribution circuit on the available fault current there. However, calculations of what the fault current would be at the distribution panel based on the cable sizes and lengths and associated circuit resistances can provide an order of magnitude estimation.

Figure E.1 in the Standard (repeated here as Figure 2) illustrates that for a typical DC system, the short-circuit current from the charger has already peaked and decayed before the short-circuit current from the battery reaches its peak. As stated earlier in this Standard, the maximum coincident short-circuit current can be conservatively calculated as the sum of the peak short-circuit current from the battery and the current-limit value from the charger. 


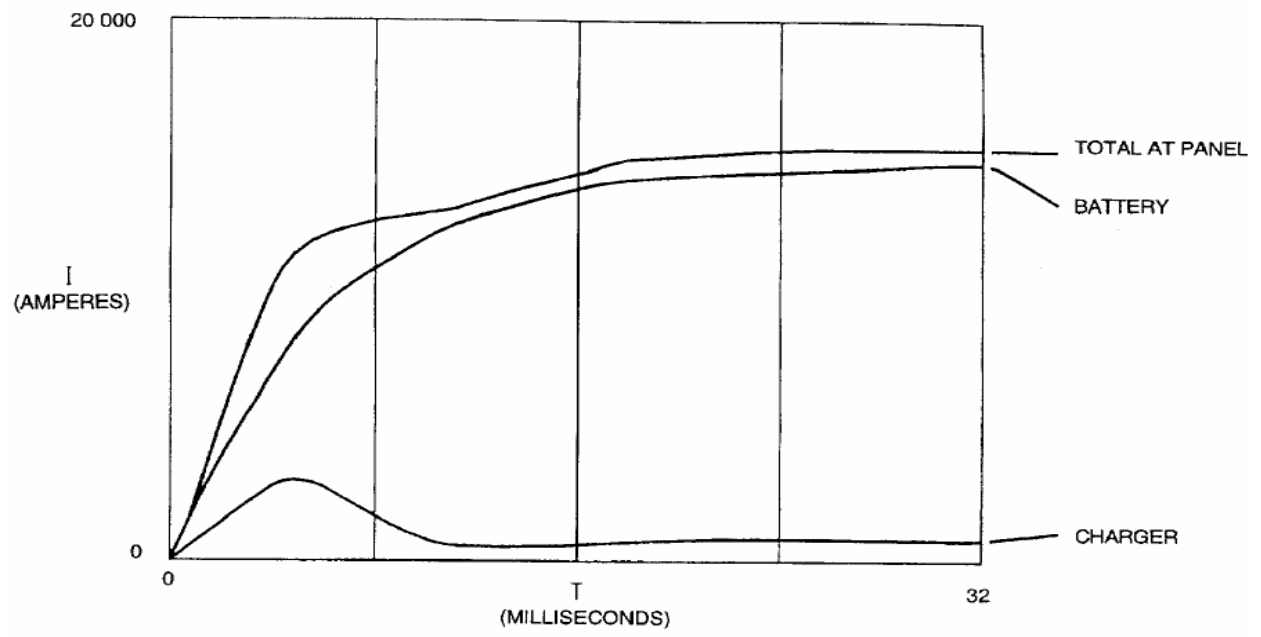

Figure E.1-Typical fault-current contributions at the dc bus with current-limited charger

Figure 2: Excerpt from IEEE Standard 946-2004

6. IEEE 1375-1998, IEEE Guide for the Protection of Stationary Battery Systems; currently, the plan is to eliminate this Standard and incorporate certain of its elements into the revision to IEEE 946.

Section 7.1 of this Guide states that: "when a charger is presented with a sudden fault at its output terminals, it provides fault current in short-term, mid-term, and long-term periods." It goes on to discuss how the magnitude and duration of currents in each period depend on the charger type, whether the charger is filtered, the response time of the current limit circuit, and the coordination and clearing time of the protective devices.

This terminology and approach is clearly different than what is put forward in IEEE 9462004; however, this Guide refers to IEEE 946 for determining the short-circuit contribution of the battery charger and its impact on the overall DC system design. There are no test reports listed in the bibliography of this Guide.

Section 6 of the Guide (for batteries) states that large batteries can discharge up to 40,000 A for several seconds. A short circuit of a storage battery initiates rapidly changing high currents and high voltage drops within the system. For lead-acid batteries, the magnitude of the fault current is dependent on the battery's resistance. Lead sulfate that forms on the plates during discharge increases the cell's resistance. The Guide goes on to say that as a lead-acid battery ages, the corrosion process acting on the grid structure of the positive plate increases its resistance, and, therefore, its fault current contribution is reduced. Aging of the battery is therefore an uncertainty in the testing program that will need to be discussed.

For battery chargers, the Guide describes the short-term fault contribution coming from the energy stored in the output filter capacitors. The effect of the type of charger is also discussed: Controlled ferroresonant chargers are inherently current limited, normally to between 2 and 3 times the rated output current of the charger. It notes that the response time of the current limit circuit to a severe overcurrent may be as long 
as $\mathbf{1 0 0}$ milliseconds. This is significantly different than what is stated in IEEE Std. 946. The mid-term fault current, which lasts until the current-limit kicks in, can be 5 to 20 times the rated output current of the charger.

The Guide also discusses fuse design and offers that fuses are sometimes misapplied in $\mathrm{DC}$ circuits.

In somewhat of a contradiction to what is stated is Section 6 of the Guide, Annex C.1.2 states that the battery charger with current limit will only provide a substantial contribution to the fault early in the event (first AC half-cycle) and its steep current rise tends to result in a shorter overall time constant.

Note that Section 8 of the Guide provides several different schemes that are deemed acceptable for stationary battery protection. We need to consider that different schemes may be employed at nuclear power plants and determine if these schemes could affect the impact of the charger and battery short-circuit contributions. This can be evaluated following the testing program.

7. IEC Standard 61660-1; "Short-circuit currents in d.c. auxiliary installations in power plants and substations", 1997. This part of IEC 61660 describes a method for calculating short-circuit currents in DC auxiliary systems in power plants and substations. The only battery charger type included in the discussion is a threephase SCR type. It considers the maximum short-circuit current that determines the rating of electrical equipment and the minimum short-circuit current used as the basis for fuse and protection ratings and settings.

When calculating the maximum short-circuit current, it assumes that the control for limiting the charger current is not effective and that the battery is charged to full capacity. When calculating the minimum short-circuit current, it assumes that the contribution of the charger is the rated short-circuit current and the battery is at the final voltage (1.75 volts/cell). The Standard also illustrates the expected short-circuit response curves (current versus time) for a charger and a battery. It states that the short-circuit current where there are several sources is found by adding the short-circuit currents of each of the different sources. (This approach is said to be a conservative approach to determining the total fault contribution.) Finally, it uses equivalent circuits to demonstrate how to calculate short-circuit currents for a battery and a battery charger. Inputs required are the open circuit voltage of the battery, the resistance and inductance of the battery, and the resistance and inductance of the conductors in the distribution circuit. The sum of the individual fault current contributors is different than what is put forward in IEEE Std. 946-2004. The testing program will address this matter and determine how conservative the approach in IEC 61660 is.

8. NEMA PE- 5-2003: Utility Type Battery Chargers; This manufacturer's standard discusses the overall design and performance expectations for constant potential battery chargers used to supply DC power from an AC source to charge a float-type battery while supplying the station load. 
Section 9.1.14 entitled "Short Circuit" discusses the ability of a battery charger to withstand a short circuit that is placed across the output terminals. The document states that the charger should operate until the internal protection opens or constant temperatures are obtained. Once the short circuit is removed and any protective devices reset or replaced, the charger should be able to return to normal service without any degradation in performance.

The Standards described here cover a broad range of information related to the protection of DC distribution systems and how the station battery and battery charger contribute current to a fault that occurs on the distribution system. Table 1 provides a summary of the salient points important to the battery and battery charger short-circuit testing program. 
Table 1: Summary of Industry Standards Information Related to DC System Faults

\begin{tabular}{|c|c|c|c|}
\hline $\begin{array}{l}\text { Industry } \\
\text { Document }\end{array}$ & Battery Info & Battery Charger Info & Comments \\
\hline IEEE Std. 141-1993 & \multicolumn{2}{|c|}{$\begin{array}{l}\text { States that procedures for DC short-circuit currents are not well } \\
\text { established and that it is necessary to consider the rate of rise of the } \\
\text { fault current as well as the interruption time in order to determine the } \\
\text { max current that will be obtained }\end{array}$} & $\begin{array}{l}\text { Lists the sources of } \\
\text { DC short-circuit } \\
\text { currents including } \\
\text { batteries and } \\
\text { rectifiers }\end{array}$ \\
\hline $\begin{array}{l}\text { IEEE Std. 242-2001 } \\
\text { ("Buff Book") }\end{array}$ & $\begin{array}{l}\text { Batteries contain little inductance } \\
\text { and, as stated by one large UPS } \\
\text { manufacturer, a shorted battery is } \\
\text { similar to a fault through a } \\
\text { resistor. A shorted battery drains } \\
\text { rapidly and gives rise to high } \\
\text { di/dt. }\end{array}$ & Refers to NEMA PE-5 & $\begin{array}{l}\text { Provides basics on } \\
\text { the nature of short- } \\
\text { circuit currents and } \\
\text { protection } \\
\text { coordination in DC } \\
\text { systems }\end{array}$ \\
\hline $\begin{array}{l}\text { IEEE Std. 399-1997 } \\
\text { ("Brown Book") }\end{array}$ & $\begin{array}{l}\text { The peak short-circuit current that } \\
\text { a battery can deliver is limited by } \\
\text { its internal resistance including } \\
\text { the intercell connectors. The rise } \\
\text { time depends on the ratio of the } \\
\text { battery's inductance to its } \\
\text { reactance (time constant). } \\
\text { Indicates an average battery } \\
\text { inductance is } 0.145 \mu \mathrm{H} / \mathrm{cell} \text { for } \\
\text { batteries larger than } 1300 \mathrm{AH} \text {. }\end{array}$ & $\begin{array}{l}\text { Refers to the statement in } \\
\text { IEEE Std. } 946-1992 \text { that for a } \\
\text { typical dc system, the short- } \\
\text { circuit current from the charger } \\
\text { will peak and decay before the } \\
\text { battery short-circuit value } \\
\text { reached its peak. Also states } \\
\text { that the magnitude and } \\
\text { duration of the short-circuit } \\
\text { current are dependent on the } \\
\text { charger design. This can result } \\
\text { in a short-term peak that varies } \\
\text { from } 8 \text { ms to } 100 \text { ms. }\end{array}$ & $\begin{array}{l}\text { Good presentation of } \\
\text { equivalent circuits } \\
\text { and sample } \\
\text { calculations for } \\
\text { batteries and battery } \\
\text { chargers. } \\
\text { "Conservative" short- } \\
\text { circuit current } \\
\text { described as the } \\
\text { battery peak current } \\
\text { plus the current limit } \\
\text { value from the } \\
\text { charger. }\end{array}$ \\
\hline IEEE Std. 666-1991 & $\begin{array}{l}\text { The equivalent circuit of the } \\
\text { battery includes the internal } \\
\text { resistance of the battery, the } \\
\text { resistance and inductance of the } \\
\text { conductors, and the battery } \\
\text { internal voltage. }\end{array}$ & $\begin{array}{l}\text { A maximum fault current equal } \\
\text { to the current limit value should } \\
\text { be used if it cannot be obtained } \\
\text { from the manufacturer. }\end{array}$ & $\begin{array}{l}\text { Total DC fault } \\
\text { current is the sum of } \\
\text { the fault current } \\
\text { contributed by the } \\
\text { individual sources }\end{array}$ \\
\hline IEEE Std. 946-2004 & $\begin{array}{l}\text { Depends on the total resistance } \\
\text { of the short-circuit path; Annex } C \\
\text { provides a way to calculate short- } \\
\text { circuit currents }\end{array}$ & $\begin{array}{l}\text { Annex } \mathrm{E} \text { describes the short- } \\
\text { circuit contribution from the } \\
\text { charger; States that the peak } \\
\text { charger and battery short- } \\
\text { circuit currents occur at } \\
\text { different times }\end{array}$ & $\begin{array}{l}\text { Total short-circuit } \\
\text { current is the sum of } \\
\text { that delivered by the } \\
\text { battery, the charger, } \\
\text { and motors. }\end{array}$ \\
\hline IEEE Std. 1375-1998 & $\begin{array}{l}\text { Batteries can discharge up to } \\
40,000 \text { A for several seconds. }\end{array}$ & $\begin{array}{l}\text { Describes charger fault current } \\
\text { in short-term, mid-term and } \\
\text { long-term periods. Also } \\
\text { depends on charger type and } \\
\text { size of output filters. Response } \\
\text { time of the current limit circuit } \\
\text { to a severe overcurrent may be } \\
\text { as long as } 100 \text { milliseconds. }\end{array}$ & $\begin{array}{l}\text { Section } 8 \text { of this } \\
\text { guide provides } \\
\text { several different } \\
\text { schemes that are } \\
\text { deemed acceptable } \\
\text { for battery } \\
\text { protection. }\end{array}$ \\
\hline $\begin{array}{l}\text { IEC Std. 61660-1- } \\
1997\end{array}$ & $\begin{array}{l}\text { Provides equations and general } \\
\text { response curve for a battery } \\
\text { short-circuit. Takes into account } \\
\text { conductor and connection } \\
\text { resistance and inductance. }\end{array}$ & $\begin{array}{l}\text { Provides equations and } \\
\text { general response curve for an } \\
\text { SCR type battery charger } \\
\text { short-circuit. }\end{array}$ & $\begin{array}{l}\text { Discusses maximum } \\
\text { and minimum fault } \\
\text { currents in DC } \\
\text { distribution systems. }\end{array}$ \\
\hline NEMA PE-5-2003 & $\mathrm{N} / \mathrm{A}$ & $\begin{array}{l}\text { Charger must be able to } \\
\text { withstand a short circuit across } \\
\text { its output terminals and be able } \\
\text { to return to normal service } \\
\text { without any degradation in } \\
\text { performance. }\end{array}$ & $\begin{array}{l}\text { Primarily associated } \\
\text { with equipment } \\
\text { specifications and } \\
\text { operating } \\
\text { parameters }\end{array}$ \\
\hline
\end{tabular}




\section{b. Journal Articles and Conference Proceedings - (Testing Related)}

1. Short-Circuit Test Results of Current Limiting SCR Type Battery Charger by Kurt Uhlir

Mr. Uhlir worked with Power Conversion Products, a former leading supplier of battery chargers to the nuclear industry, to determine the magnitude and duration of the shortcircuit currents that a battery charger was capable of delivering. The purpose of the testing was to address the concern that the current output of the charger under shortcircuit conditions may exceed its current limiting value and "thus short-circuit calculations that use the battery charger's current limiting value may be less than conservative." This testing also used different overcurrent protective devices to determine what effect the overcurrent devices would have on the chargers capability to deliver short-circuit current. The author stated that "the behavior of a battery charger during short-circuit conditions and the magnitude of short-circuit current that a battery charger is capable of delivering during short circuit has become an important factor in the design and specification of distribution equipment and overcurrent protective devices for DC auxiliary power systems." Six tests were conducted on the 300 Amp charger with the current limit set at 125\% (375 Amps); the results are summarized in Table 2.

Table 2: 300A SCR-Type Battery Charger Short-Circuit Contributions: Summary of Testing Results

\begin{tabular}{|c|c|c|c|}
\hline Test \# & $\begin{array}{c}\text { Peak Current } \\
\text { (Amps) } \\
\text { Note that the test } \\
\text { shunt was rated at } \\
3000 \mathrm{~A}, 50 \mathrm{mV}\end{array}$ & $\begin{array}{l}\text { Duration (micro } \\
\text { seconds) }\end{array}$ & Comment \\
\hline 1 & 36,000 & 0.50 & $\begin{array}{l}\text { Fuses protecting the } \\
\text { charger's SCRS opened after } \\
.970 \mu \mathrm{S}\end{array}$ \\
\hline 2 & 54,000 & 1.0 & $\begin{array}{l}\text { Fuses protecting the } \\
\text { charger's SCRS opened (time } \\
\text { not noted) }\end{array}$ \\
\hline 3 & Not recorded & Not recorded & Test equipment problem \\
\hline 4 & 48,900 & Not Noted & $\begin{array}{l}\text { Following initial peak, the } \\
\text { charger current reduced to } \\
\sim 4200 \text { amps before } 5 \text { of the } 6 \\
\text { SCR fuses opened }\end{array}$ \\
\hline 5 & 54,000 & $\begin{array}{l}\text { After initial peak, the charger } \\
\text { output decreased to } 4500 \text { amps } \\
\text { for } 7 \text { milliseconds }\end{array}$ & $\begin{array}{l}\text { Charger output returned to } \\
279 \text { amps after the fault was } \\
\text { cleared }\end{array}$ \\
\hline 6 & 58,500 & $\begin{array}{l}\text { After initial peak, the charger } \\
\text { output decreased to } 4500 \text { amps } \\
\text { for } 8 \text { milliseconds }\end{array}$ & $\begin{array}{l}\text { One of the } 6 \text { SCR fuses } \\
\text { opened reducing the output of } \\
\text { the charger }\end{array}$ \\
\hline
\end{tabular}


The author concluded that:

- The six tests demonstrated that a current limiting SCR type battery charger under load subjected to a short circuit will deliver an initial short-circuit current that can exceed the charger's current limiting capability. This value can approach 200 times the charger's rated current (300 A), nearly 60,000 A.

- The duration of this peak current (microseconds) is so short that it need not be considered in determining protective device settings.

- After the initial peak, a transient short-circuit current is present that is as high as 15 times the charger's rated output. The transient short circuit was cleared in less than 8 milliseconds through opening of the SCR fuses or the external overcurrent protection in the power supply to the charger.

2. Short-Circuit Characteristics of Large Lead Acid Storage Batteries by M. Bowman and K. Uhlir

In a September 1991 presentation to the Northeast Electric Utility Battery Conference, the authors reported on short-circuit testing that had been performed on C\&D LCR-33 batteries (one of the 3 battery types available at BNL) in May 1991. (This presentation is associated with the referenced test report B22 in IEEE 946-2004). The test configuration consisted of a 2-cell battery connected in series to a $3000 \mathrm{~A}$ disconnect switch with bus bars. A $5000 \mathrm{~A}$ in-line shunt was used to gather fault current data. The goal of the testing was to determine the effects of electrolyte temperature and starting cell voltage on the magnitude of the fault current. They found:

a. The maximum short-circuit current measured in all four tests was about half of the analytical maximum. For this particular type cell, the theoretical fault current for a zero impedance fault is 23,768 amps; the measured values were about $12,000 \mathrm{~A}$.

b. The rise time of the current was about 20 milliseconds. The fault was allowed to exist for several seconds before the test was terminated. In the test that went for 99 seconds, the fault current decreased from $12,000 \mathrm{~A}$ to $7900 \mathrm{~A}$ over that time.

c. Neither the starting cell voltage nor the value of the electrolyte temperature contributed significantly to the short-circuit current realized. (Short-circuit data based on $\left.77^{\circ} \mathrm{F}\right)$.

d. Important points made in the presentation about predicting the short-circuit current - can use rule of thumb of $10 x$ the 1-minute rating of the battery or measure the actual battery string resistance (internal battery resistance plus connectors) to calculate what the short-circuit current would be ( $\left.E / R_{\text {batt }}\right)$.

e. Battery temperature was monitored using temperature probes inserted in the electrolyte (increased from 77 to about 105 degrees. They also monitored temperatures at other points as well, including the disconnect switch $\left(82^{\circ} \mathrm{F}\right)$ and the battery cell posts $\left(97^{\circ} \mathrm{F}\right)$ for most tests. On one test of 140 seconds, the 
temperatures were: electrolyte $\left(105^{\circ} \mathrm{F}\right)$, cell post $\left(180^{\circ} \mathrm{F}\right)$, and disconnect switch $\left(215^{\circ} \mathrm{F}\right)$.

The authors recommended that additional research be conducted to:

- Test other types of cells (smaller and larger ampere-hour ratings)

- Determine what effects the external circuit has on the short-circuit characteristics, and

- Model a typical DC system installation in order to determine the effects of a battery short circuit on the design of the system.

BNL had an opportunity to follow-up with Mr. Uhlir and Mr. Wayne Johnson of EPRI who indicated that to the best of their knowledge this recommended research was not conducted.

3. Short-Circuit Current Test Results on AT\&T Round Cells at Different Temperatures by K. A. Murugesamoorthi, R. Landwehrle, and M. Migliaro

The paper states that the magnitude of short-circuit battery current is an important factor in designing DC systems including protective devices, such as fuses and circuit breakers in standby power systems. The authors were interested in assessing the effect of temperature on the available short-circuit current. They used 2 cells connected in series to a 1200 amp 2-pole disconnect switch through thick copper bus bars and used a $5000 \mathrm{~A} / 50 \mathrm{mV}$ calibrated shunt. The cells were manually shorted by closing the disconnect switch for about 5 seconds. They concluded that there was no significant change in the short-circuit current value due to temperature. Table 3 illustrates the data related to the expected short-circuit current $\left(\mathrm{I}_{\mathrm{Sc}}\right)$ versus the measured current.

Table 3: Short-Circuit Test Results of an AT\&T Battery (excerpted from paper)

\begin{tabular}{|c|c|c|c|c|c|c|}
\hline Cell Type & $\begin{array}{c}\text { Capacity } \\
\text { Ah. } \\
\text { (8 Hr.) }\end{array}$ & $\begin{array}{c}\text { Temperature } \\
{ }_{\mathrm{C}} \\
\text { (average) }\end{array}$ & $\begin{array}{l}\text { Connector } \\
\text { Resistance } \\
\text { ( } \mu \text { ohms) }\end{array}$ & $\begin{array}{c}\text { Rise Time } \\
\text { (msec) }\end{array}$ & $\begin{array}{l}\text { Current } \\
\text { Measured } \\
\text { (Amps.) }\end{array}$ & $\begin{array}{c}\mathrm{I}_{\mathrm{SC}}{ }^{*} \\
\text { (Amps.) }\end{array}$ \\
\hline List is & 1600 & 25.8 & 195 & 4 & 7030 & 10521 \\
\hline List $1 S$ & 1600 & 41.1 & 195 & 6 & 7080 & 10677 \\
\hline List 1SH & 1870 & 26.1 & 201 & 4 & 7300 & 11322 \\
\hline List 1SH & 1870 & 38.6 & 201 & 2 & 7380 & 11447 \\
\hline List 3S & 490 & 25.4 & 194 & $<2$ & 5230 & 6939 \\
\hline List $3 S$ & 490 & 39.4 & 194 & $<2$ & 5230 & 6939 \\
\hline
\end{tabular}

- assuming a zero resistance external circuit

\section{Correspondence from Power Conversion Products, 10/4/91}

In a letter from Chris Seyer of Power Conversion Products (PCP) to Florida Power \& Light dated 10/4/91, PCP describes the results of a single short-circuit test on a 130V, 300A SCR-type charger. The output was at 300A when a bolted short-circuit was applied to the output terminals of the charger. There was no battery connected to the charger- only a resistive load bank. The charger output increased to 56,800 amps for 
4 microseconds. At 14.8 microseconds, the fuses protecting the charger's SCRs blew and the charger output was reduced to zero. According to PCP, the 56,800 amps produced by the charger was the energy stored in the output filter capacitors. This could indicate that the specific design of a battery charger (size of the output filter capacitors) could influence the supplied fault current from a battery charger.

\section{c. Journal Articles and Conference Proceedings - (Non-Testing Related)}

1. Analysis of Battery Cable Faults using a Dynamic Battery Model; N. Medora and A. Kusko.

This article describes conditions, such as low battery terminal voltage, that could yield a low fault current contribution from the battery. The time delay for the protective device to actuate could result in damage including cable insulation fires because the fault current is below the threshold of the protective devices. This paper uses a battery model generated from manufacturers' data sheets to generate the appropriate terminal voltage and fault current as a function of the state of charge. It also presents design and protection measures to avoid the hazard.

Of interest is that the time to trip the circuit at the lower State of Charge (SOC) is significantly longer than when the battery is at a $100 \%$ SOC (examples provided in the paper show 2 orders of magnitude higher time - 15 seconds versus 0.15 seconds.) Resulting temperatures reach the melting point of copper $\sim 1080^{\circ} \mathrm{C}$ ). The author's conclusions are provided below:

a. During the protection and co-ordination study, the internal resistance of the battery as a function of SOC must be taken into account when coordinating battery cable size with the time-current characteristics of the protective device.

b. For ampacity-based cables, where the power density is relatively high, the cable voltage drop per meter length is relatively high. For voltage drop-based cables, where the power density is relatively low, the cable voltage drop per meter length is low.

c. When a cable is selected such that the ratio of the voltage drop to the crosssection area is relatively high, the power density will probably be high, and consequently under fault conditions, with a low SOC on the battery, the cable temperature rise may be excessively high.

d. When a cable is selected such that the ratio of the voltage drop to the crosssection area is relatively low, the power density will probably be low, and consequently even under fault conditions, with a low SOC on the battery, the cable temperature rise is minimal.

e. For ampacity-based cables, where the power density is relatively high, it is important that the cable be adequately sized for normal operation. The fuse must be selected to provide appropriate protection under all conditions including low battery SOC. It may be prudent to also provide an additional measure of safety perhaps by using an under-voltage protection circuit, to monitor and possibly 
disconnect the battery (not for nuclear plants) when the SOC decreases below a pre-determined level.

2. Stationary Battery and DC Power System Electrical Protection Design Considerations; K. Uhlir

This paper presented at the 2003 Battcon Conference describes the options available when engineering and providing the electrical protection for the stationary battery and the DC distribution system. The short-circuit characteristics of DC power sources are also discussed.

This paper along with several others makes the point that published data for protective devices is often misused. That is, the AC rating is often given but that is not necessarily the same rating for DC applications, especially when evaluating the overcurrent and fault conditions under which the protective device is expected to operate. The other important difference in the application of protective devices between AC and DC systems is that the DC system often has two competing goals:

- to minimize the risk of load and power source damage from a fault, and

- minimizing the number of service interruptions of the DC power sources. The latter is relevant to nuclear power plant applications that look upon the DC system as the power source for emergency conditions.

The author points out that the time constant is the DC circuit parameter most often overlooked when evaluating protective devices. The time constant gives a measure of how quickly the current will rise in a fault condition. The fault current will reach its maximum in about 5 time constants. The typical time constant in a DC circuit is about 10 milliseconds (ms) so fuses are often rated for a $10 \mathrm{~ms}$ time constant. However, if the circuit time constant is longer than $10 \mathrm{~ms}$ (higher inductance) the fuse may not be acceptable.

The paper refers to IEEE Std 946-1992 for additional guidance on the available shortcircuit current from a battery and battery charger and to IEEE Std 1375-1998 for guidance on overcurrent protection for a stationary battery system. The author points out that the short circuit of a battery (considered to be a finite power source) depends on the resistance of the path, and the state of charge and internal resistance of the battery. He goes on to say that the internal resistance depends on variables, such as the material and dimensions of the grids and terminal posts, the surface area and composition of active material, the specific gravity, and the thickness of the separators.

\section{EPRI Stationary Battery Guide; Chapter 7- DC Power Protection. EPRI Project} Manager- W. Johnson

This chapter in a larger report about stationary batteries describes the nature of DC system faults and the various protective devices available to minimize the consequences of such an event. It states that DC faults are more dangerous because 
the DC system protective devices must be capable of clearing the fault without the benefit of the zero crossing that an AC sinusoidal current exhibits.

The amount of short-circuit current available from a battery depends on the number of plates, the surface area of the plates, the state of charge, and the ampere-hour capacity of the battery. They offer the frequently published conservative method of estimating the battery short-circuit current as 10 times the 1 minute capability of the cell, and states that the current will take longer to reach its peak when the circuit inductance is increased. In that regard, they state that a typical battery will have a time constant less than $5 \mathrm{~ms}$, but the time constant for the entire distribution circuit could be $15 \mathrm{~ms}$ or more depending on the fault location.

The battery charger short-circuit contribution is also described in this report. Depending on the charger size and design, this report indicates that the amount of current can be significant. The output filter capacitors will immediately discharge into the fault, resulting in a current spike of micro seconds duration with an exponential decay. Until the current limiting features takes effect (within milliseconds), the charger contribution into the fault is limited by its basic design and internal resistance. The report goes on to say that controlled ferroresonant chargers are usually current limited to within two to three times the rated output of the charger with a very fast response time. SCR type chargers have very little inherent current limiting and may have an initial fault current of nearly twenty times the rated charger output current for the 15 to 100 milliseconds it takes the current limiting circuit to respond. The report goes on to state that the current limit depends on the design of the circuit.

The clearing time of the battery charger protective devices may also dictate how much current the charger contributes to a fault. The EPRI report notes that chargers that use circuit breakers tend to have longer clearing times than fuses and, therefore, contribute more current to the fault over time.

The report provides an example of a short-circuit calculation for a DC distribution system and states that the fault current available at any location depends on:

- The location of the fault,

- The resistance between the battery and the fault,

- The battery state of charge, and

- The battery charger contribution to the total fault current.

The EPRI report takes the position that if the sum of the available short-circuit current from the DC sources is less than the rating of the system protective devices, no further analysis should be necessary. The report provides a simple circuit and sample calculation for analyzing the current contributions from a fault. 
The resistance of the battery limits the short-circuit current to the maximum value that is typically provided by the battery vendor. However, in Figure 3, taken from the EPRI report, the resistance of the cables and connections must also be taken into account when estimating the expected overall fault current at any location.

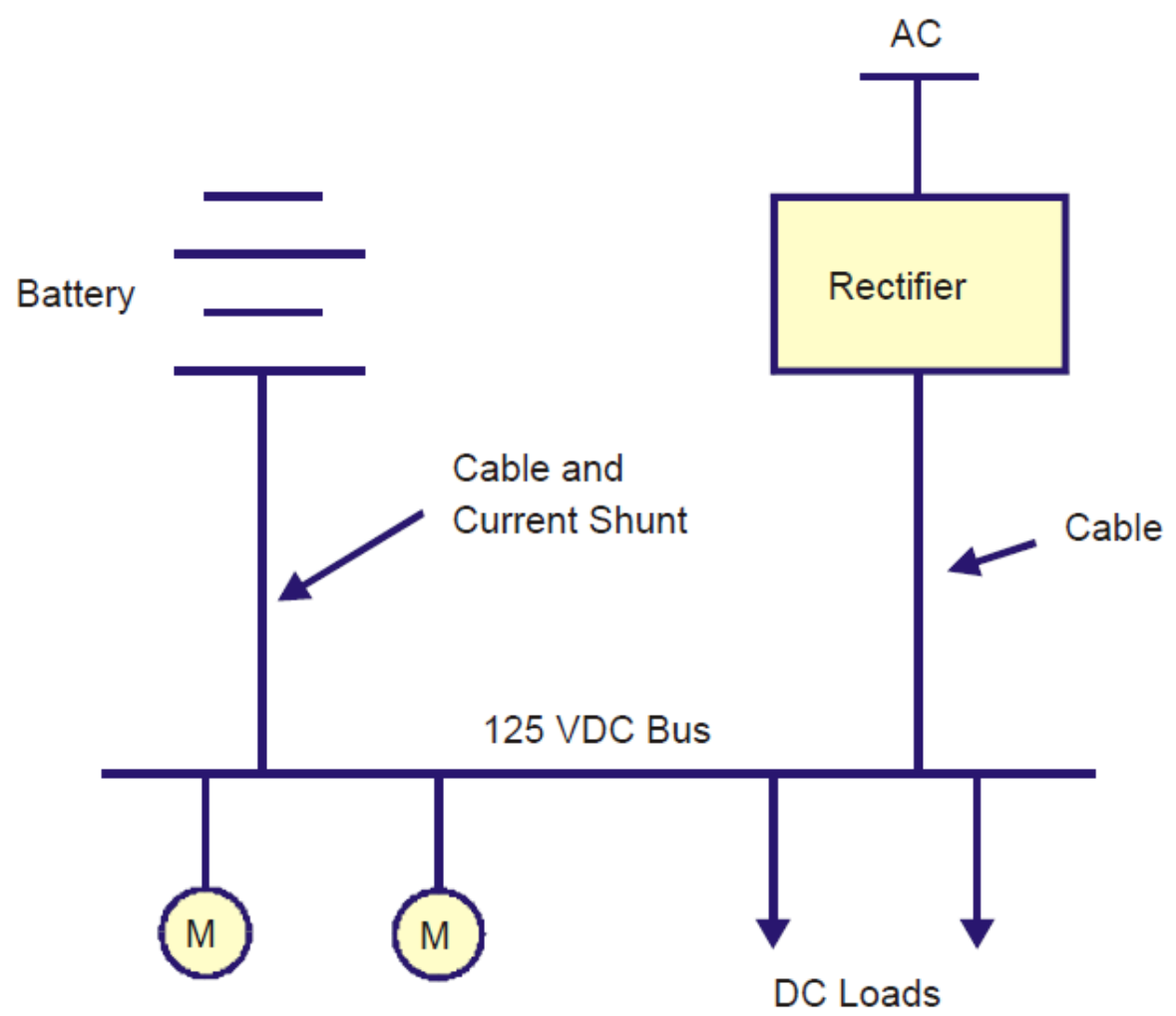

DC Motors

Figure 3: Example DC System for a Fault Study (EPRI TR-100248)

4. Understanding Short-Circuit Currents in DC Power Systems When Used in Conjunction with Standby Batteries; R. Mollet, D. Law, and H. Scoggin

This paper, while focusing on telecommunications equipment, presents some interesting information on battery short-circuit currents and the need for overcurrent protective devices that can handle these large currents. The statements of interest relevant to our project are:

- The short-circuit capability in standby DC power systems is heavily dependent on the internal resistance of the battery plant utilized in each system.

- The internal battery resistance is a result of many design variables, such as:

- Separator material and porosity

- Spacing between plates

- Strength of the electrolyte 
- Surface area of the plates

The paper states that: "Therefore the maximum short circuit that a battery can deliver, assuming a zero impedance fault, is based on the battery's internal resistance and the effective emf (terminal voltage) of the battery."

In their calculations, they assume that the charger short-circuit current contribution peaks well before the battery short-circuit current peaks. It uses the current limiting value as the long-term contributor from the charger.

They conclude that there is a need for additional industry standards covering DC power system design. One of the references is a C\&D document, "Battery Short-Circuit Current," Publication RS-1468, dated 3/96-I discussed in Section II.d - Vendor Information.

Finally, the paper discusses the need for selective and coordinated protective relaying to minimize the effects of a fault on the DC distribution system.

\section{Short-Circuit Current Calculations for DC Systems by A. Berizzi et al (1996)}

This paper also references the IEC Standard 61660-1 in its discussion. It states that the IEC standard deals with the calculation of some characteristic quantities that can describe the time variation of the currents at the short-circuit location from the initiation of the short circuit to its end. The load current is not taken into consideration when calculating the short-circuit current. An important point that it raises is that it is necessary to distinguish between two different values of short-circuit current:

- The maximum short-circuit current that governs the rating of electrical equipment, and

- The minimum short-circuit current that can be taken as the basis for fuse and protection device ratings and settings

The paper contains the typical short-circuit current response curves for a converter, a battery, a capacitor and a motor and discusses the use of the software "EMTP" on a test network. Unfortunately, the details of the test network are not provided so it is difficult to determine the usefulness of this software on a nuclear power plant DC distribution system.

6. Transient Analysis of Auxiliary DC Installations in Power Plants and Substations, S. Skok et al

This paper focuses on telecom applications, but there are some similar system designs to what exists in a NPP. It deals with the risk of power system blackout caused by wrong selectivity of protection devices (similar to what transpired at Palisades). It references IEC Standard 61660 and suggests changes to it. It mentions testing that has been performed but contains only two tables that show the results of a specific DC 
configuration. BNL has tried to contact the authors in Croatia for further information. At the time of this report, no response has been obtained.

7. Stationary Battery Charger Specifications Demystified by W. Bennett; HindlePower Inc.

This paper presented at the 2003 Battcon Conference is focused on battery chargers but also discusses its link to the station battery and the DC distribution system. It discussed two types of protection built into a charger. First, there is active protection, such as current limit. Then there are passive devices, usually circuit breakers or fuses. It states that "An active current limit circuit is a capable defense to protect the charger from a fault on the DC bus". It goes on to say that the filter capacitors, discharging into a DC bus fault will undoubtedly clear any DC fuses in the output circuit. It also recommends that if the battery short-circuit capability is more than $5000 \mathrm{~A}$, a high AIC (high interrupting current) breaker should be specified for the battery charger.

\section{Battery Protection Methods-Important Variable to Consider by R. Setchell et al.}

This paper presents recommended battery protection practices to accurately protect the battery and associated DC distribution system. It expands on the short-circuit coordination issue by discussing DC short-circuit protection scenarios and the subsequent application and selection of battery protection devices, including downstream circuit breaker coordination. The following summarizes the main points of the paper:

- In its discussion of battery contribution to a short circuit, it states that: The worst case short-circuit analysis is a battery at equalize voltage without external cell-tocell resistances resulting in conservative sizing of protective devices, and "Battery short-circuit current is an important variable to the designer and is required to evaluate short-circuit scenarios and the battery protection device".

- Each battery string should have a short-circuit current rating that can be used to determine the required AIC. "Without this information, the designer cannot properly select the protection device, since battery short-circuit current values vary dramatically".

- The paper has two DC Plant Short-Circuit Case Studies to demonstrate how best to design protective devices in a DC Distribution System.

9. Overcurrent protection of DC Power Plant Equipment using modern high performance current limiting fuses by Ron Mollet (Bussman)

This paper focuses on the specifics of fuse design and states that safe and reliable overcurrent protection can best be achieved through the use of properly sized and selectively coordinated fuses which dramatically limit the magnetic forces and thermal energy associated with high current short-circuit faults. 
The author concludes that safe and reliable overcurrent protection can best be achieved through the use of current limiting fuses which limit the magnetic forces and thermal energy associated with high current short-circuit faults.

\section{DC Overcurrent Protection - Where we Stand by James Brozek (Bussman)}

This paper focuses on proper fuse selection in a DC distribution system. He states that: "For most battery protection applications, the fuse operation is straightforward and reliable. Batteries contain very little inductance and, as stated by one large UPS manufacturer, a shorted battery is similar to a fault through a resistor. A shorted battery drains very rapidly and gives rise to high $\mathrm{di} / \mathrm{dt}$. ."

The author discusses the circuit time constant and how a long time constant can be problematic if the fuse does not operate quickly enough. For a circuit with a given resistance, a large inductance will cause a slow rate of current rise and negligible inductance will yield a fast current rise. The maximum value to which the fault current will rise is limited by the circuit resistance. As a rule of thumb, DC circuits at rated voltage, having time constants less than 5 milliseconds, will have short-circuit melting and clearing characteristics similar to AC circuits.

\section{Battery Protection - Where do we stand? By Richard Nailen}

This widely referenced paper written in 1991 is critical of the lack of standardization for protective coordination in DC distribution systems, focusing on fuse protection.

Some excerpts from the paper that are of relevance to this project are:

- Available short-circuit current can be tens of thousands of amps - vaporization of large conductors is possible if the fault is not interrupted quickly.

- The basis for calculating available short-circuit current is the so-called "oneminute current" rating of the battery.

- The paper discusses at length the proper fusing protection of large DC circuits and cautions about using AC interruption ratings in DC systems.

- The author discusses the inadequacy of industry standards for DC Distribution System Protection including the following observations: (a) IEEE Standard 946 is the only IEEE standard that deals with circuit protection for battery systems but only in general terms; (b) Article 480 of the National Electric Cod applies to all stationary battery installations but says nothing about battery circuit protection; and (c) UL 1778 titled UPS Equipment, states that "the battery supply circuit shall be provided with acceptable rated DC overcurrent protection to reduce the risk of fire and electric shock resulting from overload or short-circuit conditions". But just how such ratings were to be arrived at is not specified nor are test procedures given. 
- The author depicts the circuit time constant: for battery circuits, the typical time constant is between 10 and 80 milliseconds. Fault currents rise exponentially towards a value equal to the circuit voltage divided by the circuit resistance; $I=(V / R)-A E^{-(R / L) t .}(A$ is the circuit current flowing at the time of the fault.)

- Low current battery system faults are more common than the bolted fault short circuit. A fuse that interrupts relatively less predictably on low current can be troublesome for DC distribution system reliability.

- The author concludes by emphasizing that even though there are a number of standards related to DC components and systems, "we clearly need a 'protection standard' offering recommendations concerning protective methods, and guidelines on protective device selection, to fill an important gap in the literature."

12. DC Control Battery System Protection and Coordination by Robert Smith

Battery system failure jeopardizes a power system by eliminating the DC control power source for AC system circuit breakers and protective devices. Failure to protect DC system components could also result in disastrous consequences for the battery system itself. This paper reviews the protection of DC distribution system components including the battery, battery charger, and distribution circuits and discusses an optimum approach for protecting them.

The article states the current limit feature of the battery charger protects the charger from feeding a DC system short circuit with more current than the charger rating. The charger circuit breakers and fuses should be sized for the charger maximum rating and the available system short-circuit current.

Overload and short-circuit protection for the DC system should be provided by either circuit breakers or fuses sized to protect the conductors supplying the load. Such protective devices need to be coordinated with source protective devices (battery and battery charger for example). This protection operates selectively to isolate the faulted circuit with minimal disruption to the DC distribution system. The paper provides several illustrations of DC distribution systems along with samples of the coordination curves for the individual breakers and fuses used to achieve selectivity.

\section{The Effectiveness of Using IEC 61660 for Characterizing Short-Circuit Currents of}

Future Low Voltage DC Distribution Networks by A. Emhemed and G. Burt

While this paper is not directly related to $\mathrm{DC}$ distribution circuits that might be employed in nuclear power plants, it was reviewed due to its currency (June 2013) to determine the philosophy associated with new system designs and installations called low voltage direct current (LVDC). It is interesting to note the author's statement: "To date, there are no comprehensive standards for how to characterize LVDC short-circuit currents and how to protect $L V D C$ circuits optimally".

The authors discuss the use of IEC 61660 that was formulated to provide a calculation method for DC short-circuit currents in auxiliary DC installation in power plants and substations and evaluate its effectiveness in an LVDC network. They used the PSCAD/EMTDC simulation program to model a test network and used an Insulated Gate Bipolar Transistor (IGBT) type charger as one of the contributors to the system 
fault current. They found that the using the calculation method in the Standard was effective in estimating steady state faults but less accurate when characterizing capacitor discharging currents from battery chargers. They concluded that if an LVDC network is designed in accordance with IEC 61660, the real network will experience a higher fault current with a longer decay time than calculated. This could be an issue in terms of equipment ratings.

\section{Battery and DC Backup System Protection Coordination by Haissam Nasrat; 2011 InfoBATT conference presentation}

The author states that $99 \%$ of all available literature about protection coordination is for AC applications; very few cover DC faults. In a typical DC backup system, multiple sources of energy are connected in parallel contributing to the fault simultaneously. Each source has a different time constant and amplitude and even the effect of a DC fault on the AC main should be taken into consideration.

Two objectives are that the breakers and fuses need to open "selectively" and the cables, switches, bus bars etc. need to be designed to withstand the fault energy. During a fault evolution, the system voltage will decay at a rate that is related to the impedance of all parallel sources over the period of time from the initiation of the fault to the operation of the protective devices (a difficult calculation according to the author).

For a battery charger, the magnitude of the fault depends mainly on the AC mains impedance, the power transformer impedance, the inductive filter design and, as a rule of thumb, will provide 15-20 times the full current rating with a time constant of about 25 milliseconds.

\section{Handbook of Electrical Calculations, Section 18 by M. Migliaro.}

The section on calculating battery short-circuit current states that the short-circuit current can be calculated by dividing the open circuit voltage of the cell by its internal resistance. Vendors supply the internal resistance, but it can also be calculated as described in this section of the handbook.

It briefly discusses the "rules-of-thumb" that are used to estimate the short-circuit current obtained from a battery on a DC system fault. The first is 10 times the battery one-minute rating and the second is 20 times the three hour capacity; both of which can be obtained from battery fan curve of amps per positive plate versus amp-hours per positive plate. Both are conservative (higher than what would actually be experienced in a fault condition).

\section{d. Vendor Publications and Communications}

1. Correspondence and Information from Enersys and sample page from Enersys Publication No. US-GN-RS-002, February 2012:

The Enersys Director of Engineering indicated via email correspondence that Enersys had performed some short-circuit testing on their batteries, but do not have a specified program for doing so. In their testing, they connected a parallel group of (4) or (6) 4/0 cables (depending on the cell size) through a large knife switch, a 10,000 amps shunt, 
and a parallel arrangement of large slow blow fuses. By judicious choice of the fuses they can select a run time sufficient to protect the setup from overheating.

They found that the maximum current falls very quickly, but does stabilize at about $1 / 2$ volt and $25-40 \%$ of the max current for a good number of seconds. They found that the idealized zero resistance short circuit can never by achieved in test space.

The basis of their published values, therefore, comes from IEEE 946, Annex C and the related IEC documents. They generate an IV line, from which they determine the internal resistance. They then establish an effective open circuit voltage value based on the specific gravity of the cell, and compute the short circuit as the effective open circuit voltage divided by the internal resistance.

Their latest literature which includes their numbers for the calculated values for the internal resistance $\left(R_{\text {int }}\right)$ and the short-circuit currents $\left(I_{s c}\right)$ are shown in Figure 4. Note that the cells used at BNL that were provided by Enersys are the $2 \mathrm{GN}-23$ model that has an ideal short-circuit current of 18,690 amps. The Ideal short-circuit current assumes no connector resistance.

\begin{tabular}{|c|c|c|}
\hline & ${ }^{*}$ Resistance & Isc \\
\hline $\begin{array}{l}\text { PowerSafe- } \\
\text { GN Battery } \\
\text { Size }\end{array}$ & Milliohns & Amps \\
\hline $2 \mathrm{GN}-13$ & 0.213 & 9390 \\
\hline $2 \mathrm{GN}-15$ & 0.171 & 11700 \\
\hline $2 \mathrm{GN}-17$ & 0.155 & 12900 \\
\hline $2 \mathrm{GN}-19$ & 0.136 & 14710 \\
\hline $2 \mathrm{GN}-21$ & 0.120 & 16670 \\
\hline $2 \mathrm{GN}-23$ & 0.107 & 18690 \\
\hline GN-25 & 0.105 & 19050 \\
\hline $\mathrm{GN}-27$ & 0.100 & 20000 \\
\hline GN-29 & 0.093 & 21510 \\
\hline GN-31 & 0.089 & 22470 \\
\hline GN-33 & 0.086 & 23260 \\
\hline GN-35 & 0.076 & 26320 \\
\hline GN-37 & 0.073 & 27400 \\
\hline GN-39 & 0.071 & 28170 \\
\hline GN-41 & 0.069 & 28990 \\
\hline $\mathrm{GN}-43$ & 0.066 & 30300 \\
\hline GN-45 & 0.064 & 31250 \\
\hline
\end{tabular}

Figure 4: Sample Battery Vendor Short-Circuit Data (Enersys Publication)

2. "Battery Short-Circuit Current", RS 1468, C\&D Charter Power Systems Inc., March 1996.

This publication from C\&D describes the short-circuit characteristics of lead acid batteries and provides examples for calculating the available short-circuit current from a battery.

It states that the following parameters are important to the transient and steady state response of a battery under short-circuit conditions:

- Capacitance of the battery,

- Inductance of the battery and the DC distribution circuit, and 
- Electrochemical response of the battery

Similarly, the maximum short-circuit current that a battery can deliver, assuming a zero impedance fault, is based on the battery's internal resistance the effective emf of the battery. The total resistance of the battery is equal to the sum of the internal resistance of all the series-connected cells, plus the resistance of the intercell connectors.

Effect of Aging: Other factors that affect the resistance of the lead acid battery are its state of charge (SOC) and its age. As the lead acid battery ages, the corrosion process acting on the grid structure of the positive plate increases its resistance and therefore reduces the short-circuit current produced. No quantification of this effect was found in the literature.

Battery Current Characteristics: The C\&D publication states that during the first 15 milliseconds of a short circuit, the capacitance and inductance of the battery influences the transient response. After this time, the steady state current is determined primarily by the resistive network of the battery and the DC distribution circuit. It goes on to say that when a battery is subjected to a short circuit, the current rises to a peak value within 5 to 15 milliseconds exhibiting a time constant of 1 to 3 milliseconds depending on the circuit inductance (DC motors). Figure 5 from the publication illustrates this response.

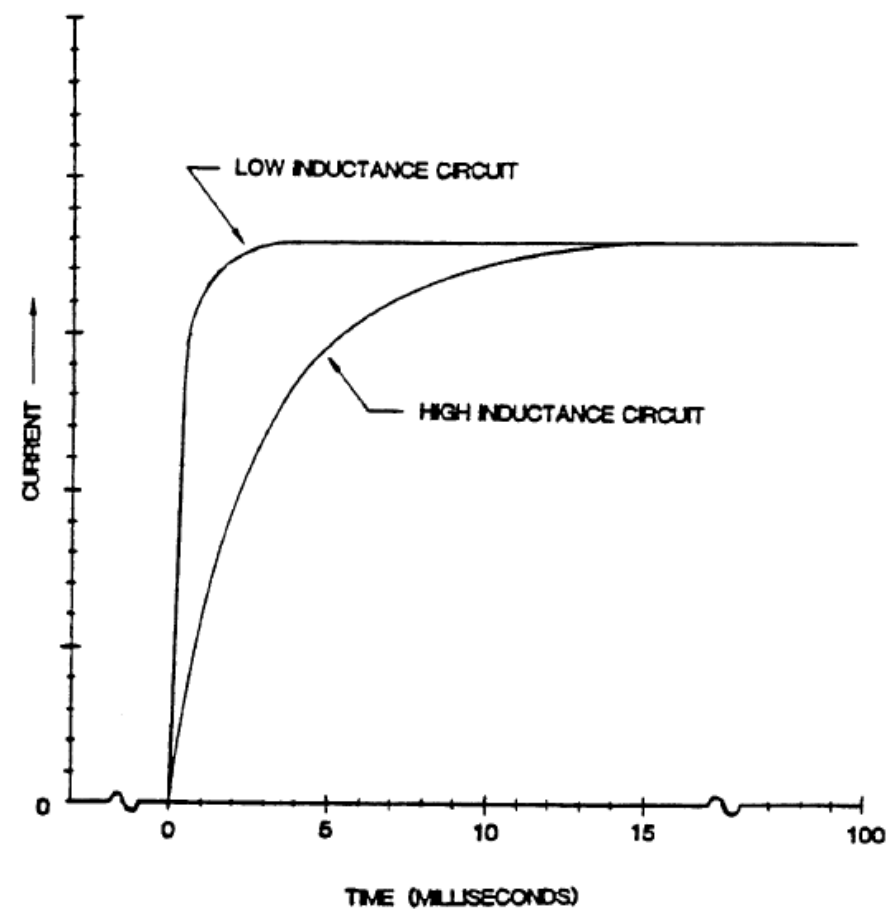

Figure 5: Early Battery response to a short circuit (C\&D)

Battery Withstand Capability: C\&D indicates that larger cells like the ones being tested at BNL should be able to sustain a short-circuit current for several minutes, "or even the many hours it would take to completely discharge the battery". They state that after 
approximately 100 milliseconds, the battery voltage will remain relatively constant for several seconds, then slowly decline as the transport of electrolyte to the reacting zones of the electrodes becomes limiting.

Having indicated that the battery can withstand a short circuit, C\&D cautions in this publication that there are potential weak links that could produce undesirable results, including:

- Failure of the terminal post: The terminal can melt either above or below the cell cover producing an arc that could ignite the cell cover and/or the hydrogen in the head space beneath the cover.

- Failure of the intercell connection: Connectors outside the cell could melt, opening the battery circuit.

- Heat generation: The heat generated in the cable connectors can melt the insulation or the solder in the terminal lugs.

Calculating Available Battery Short-Circuit Current: C\&D indicates that tests have shown no appreciable impact on the magnitude of the short-circuit current at elevated temperatures or at elevated terminal voltages. The paper provides two sample calculations for determining the current from a bolted short-circuit at the battery terminals and one that occurs at the main distribution bus with no charger or motor contribution. The bolted short-circuit example assumes no DC distribution circuit resistance or inductance. Overall, this publication presents the theoretical contributions of a battery short-circuit rather than actual experience or testing results.

\section{Correspondence from C\&D to FP\&L dated 7/30/91}

In response to a request from FP\&L for battery charger short-circuit information, C\&D restated the questions as: What is the output current of the charger during the first few cycles of turn on if a short exists across the charger output terminals?

C\&D responded with a couple of statements that are of interest to this project:

a. C\&D does not have characteristic curve for the current limiting control to show a time versus current response time to overloads.

b. "If the short circuit is applied while the charger is operating, the current limit will hold..."

c. C\&D also stated that: "Keep in mind that a short circuit across the battery will draw several thousand amperes from the battery causing fuses to open in the battery string".

Note that C\&D did not answer the question from FP\&L about whether the charger could ever deliver more current then the maximum current limit setting, even for a very short period of time. 


\section{DISCUSSION}

\section{a. Other Considerations}

Other information and inputs that are factored into this research are summarized below.

\section{Electrical Distribution System Functional Inspections (EDSFI)}

The NRC Inspection Manual contains a detailed description of a process used to assess the capacity of the electrical distribution system to perform its intended functions during all plant operating and accident conditions. Included in this inspection are requirements to determine the:

- Adequacy of short-circuit calculations, design of protective relay logic and relay setting calculations, grounding calculations and schemes, and protective device coordination studies, and

- Correctly chosen setpoints for overcurrent protective relays to assure proper breaker coordination.

BNL was not able to determine from the several inspection reports that it reviewed whether any issues were found with the above inspection areas for the DC distribution system. The reports reviewed included Calvert Cliffs (1993), Indian Point 2 (1991), Kewaunee (1992), and more recent inspection reports that contained information about EDSFI findings including Monticello (2004), Nine Mile Point 2 (2002), V. C. Summer (2004), Waterford (2003), and Watts Bar (2011).

Some past NRC documentation, however, did raise some general concerns similar to what was noted in the literature discussed previously. Information Notice 91-29, Supplement 1 describes deficiencies identified during the EDSFIs. Two that are related to this project and previously described in Generic Letter No. 88-15, "Electric Power Systems-Inadequate Control Over Design Processes," had to do with the inadequate interrupting capacity of fault protection devices (Indian Point Unit 3) and improper coordination of fault protection devices (McGuire Units 1 and 2). Knowing the battery and battery charger fault contributions are essential elements of obtaining the correct interrupting rating and settings for the protective devices used in the DC distribution system.

At Indian Point Unit 3, the calculated fault current for the $125 \mathrm{Vdc}$ power distribution panels was 16,600 Amps, with an additional 2000 Amps available from the battery chargers. The molded case circuit breakers protecting these panels were manufactured before 1976 and could not be certified by the manufacturer for more than 10,000 Amps. The inspectors found that this deficiency was caused by a recent replacement of the station battery and battery charger with equipment having a higher short-circuit contribution.

At the McGuire units, the $125 \mathrm{Vdc}$ circuit breakers were found to be incorrectly coordinated such that a fault on a branch circuit could cause the $400 \mathrm{~A}$ main feeder circuit breaker to open, thereby separating the battery and charger from the $125 \mathrm{Vdc}$ 
distribution center. This would result in a loss of $125 \mathrm{Vdc}$ and vital $120 \mathrm{Vac}$ power for the instrumentation and control of one train for both Units 1 and 2.

\section{b. Battery Chargers in Use}

Four sources of information were reviewed to determine the distribution of battery charger types currently being used at nuclear power plants.

- Battery charger failures reported in the EPIX database: 120 charger equipment failures were reported from $1 / 1 / 2000$ to $4 / 1 / 2013$. The distribution of these reports were Power Conversion Products (PCP)-46; C\&D-37; with Solidstate Controls, Cyberrex, Exide, ELTRA and GNB identified as the Manufacturer for the remaining 37 events. The Model $3 \mathrm{~S}-130$ was the predominant type for PCP; the ARR 130 the predominant type for C\&D.

- A Sandia Report published in 1994 (SAND93-7046, Aging Management Guideline for Commercial Nuclear Power Plants-Battery Chargers, Inverters, and Uninterruptible Power Supplies) contained a table of battery charger types in use at nuclear power plants. The data were obtained from the Nuclear Plant Reliability Data System (Table 4).

Table 4: Battery Charger Types Used in Nuclear Power Plants (1994 Source)

\begin{tabular}{|c|c|c|}
\hline Manufacturer & Type & $\%$ in Use \\
\hline Power Conversion Products & SCR & $33 \%$ \\
\hline Exide & SCR & $24.5 \%$ \\
\hline C\&D & SCR and Ferroresonant & $20.5 \%$ \\
\hline ELTRA & SCR & $5.2 \%$ \\
\hline GNB & SCR & $4.0 \%$ \\
\hline Solid State Controls & Ferroresonant & $3.1 \%$ \\
\hline Cyberrex & SCR & $2.8 \%$ \\
\hline LaMarche & Magnetic Amplifier & $2.4 \%$ \\
\hline Westinghouse & Not identified & $1.8 \%$ \\
\hline
\end{tabular}

- 10 CFR 21 Notification, 7/11/2006. Nuclear Logistics Inc. (NLI), the nuclear supplier for Power Conversion Products battery chargers, identified 9 nuclear power plants that had PCP chargers manufactured between October 2002 and June 2006. AZZ took over NLI in 2012 and notes on its web site that NLI is the authorized nuclear supplier for both PCP and C\&D battery chargers.

- The most recent document, supplied by NRC to BNL from the EPIX database. The EPIX database is a comprehensive list of all of the battery chargers used in nuclear power plants along with their in-service dates and model numbers. BNL culled out those associated with the Class 1E DC distribution system and did not include those chargers associated with emergency lighting or other sub system applications. The class IE charger types used in the DC distribution systems are summarized in Table 5. 
BNL Technical Report

BNL-107800-2015-IR

Table 5: Class IE Battery Chargers- EPIX Database (2014)

\begin{tabular}{|c|c|c|}
\hline Manufacturer & Model & Quantity \\
\hline \multirow{4}{*}{ Power Conversion Products } & SC-24-25 & 13 \\
\cline { 2 - 3 } & 3S-130-300 & 10 \\
\cline { 2 - 3 } & 3S-130-400CE & 10 \\
\cline { 2 - 3 } & 3SD-130-100CE & 10 \\
\cline { 2 - 3 } & SCR & 10 \\
\hline Solid State Controls & BCS 12200 & 10 \\
\hline Cyberrex & 130400R3S & 12 \\
\hline Exide & UPC-130-3-400 & 10 \\
\hline GNB (Gould) & GRF 120T250F30 & 12 \\
\hline \multirow{3}{*}{ C\&D } & ARR130K300 & 12 \\
\hline & ARR130K300F & 12 \\
\hline
\end{tabular}




\section{SUMMARY AND RECOMMENDATIONS}

The response to a fault on the DC distribution system at a nuclear power plant can have a significant impact as seen by the event that occurred at the Palisades Plant in September 2011. The approach that nuclear power plants take to minimize the impact of such a fault is derived from industry consensus documents, such as IEEE Standard 946-2004, IEEE Recommended Practice for the Design of DC Auxiliary Power Systems for Generating Stations. It is important that these recommended practices be based on a strong foundation of analyses, testing, and experience. In the case of the typical configuration of a battery charger and battery connected in parallel to support critical equipment and instrumentation in a nuclear power plant, it appears that additional analyses and testing are warranted to understand their combined contribution to a DC fault event.

The detailed literature review completed by BNL noted the following:

1. Many papers published in the 1990 s and even one published as recently as 2013 indicate that there is not a standard method of approaching the short-circuit protection and coordination of critical DC distribution system protection devices. One of the reasons for this is that there has been very little empirical data made available to quantify the short-circuit currents that a battery and a battery charger will contribute in combination. Therefore it appears that the assumptions of the supplied fault current from batteries and chargers could be different. This could lead to different settings for protective devices and different plant responses to a fault on the DC distribution system.

2. Testing has been performed individually on two battery types (C\&D and AT\&T) and one battery charger type (PCP SCR type). These tests revealed that the measured short-circuit currents are less than the calculated values, sometimes by a factor of 2 , due to circuit impedances and battery voltage response.

3. There are several different types and sizes of battery chargers being used at nuclear power plants. How each is protected to withstand a fault condition and how each would contribute to such a fault may be different. The statement in IEEE Std. 1375-1998 that a battery charger will provide fault current values in short-term, mid-term, and long-term periods will be explored in this test program by monitoring the battery charger fault response using high-speed data acquisition equipment.

4. A battery's theoretical short-circuit contribution is attainable from the battery vendor's specification sheets. However, this same information is not readily available from the battery charger vendors. This could be due to the prevalent wisdom that the battery contribution to a DC distribution system fault will dominate that from the charger even though limited testing indicates that a charger can provide a fault current contribution that is similar in magnitude to the battery for a short time. 
5. The NRC/BNL testing program will not be examining a fault at the distribution panel resulting in some uncertainty about the impact of the actual distribution circuit design on the available fault current at the panel. However, calculations of what the fault current would be at the distribution panel based on the cable sizes and lengths and associated circuit resistances can provide an order of magnitude estimation. Nor will we be testing the effects of aging on the fault contribution from the battery or the charger. As indicated by IEEE Standard 1375-1998, as a lead-acid battery ages, the corrosion process acting on the grid structure of the positive plate increases its resistance, and therefore its fault current contribution is reduced. Aging of the battery and the charger is therefore an uncertainty in the testing program that will need to be discussed in the final report.

6. The DC distribution circuit can influence the magnitude, characteristics, and potential consequences of the fault current produced by the battery and the charger. The rate of rise, for instance, of the fault current could impact the speed at which protective devices react and therefore the time that conductors and connectors are exposed to these high currents. The rate of rise and associated time constant will differ due to the DC circuit inductance.

7. Assuming greater values than the actual fault currents that will occur could result in higher ("conservative") settings for protective devices that may have unintended consequences during a fault. The literature indicates that a lower fault current can increase the response time of the protective device enough to cause a fire if the setting of the protective device is too high. Using "rules of thumb" for the battery short-circuit contribution as described in several standards rather than more realistic values may not be appropriate for nuclear power plant applications where high reliability and availability of safety-related components is essential. 